\title{
Potential role of mycorrhizae combined with Pinus tabuliformis in repairing soil contaminated by lanthanum and cerium
}

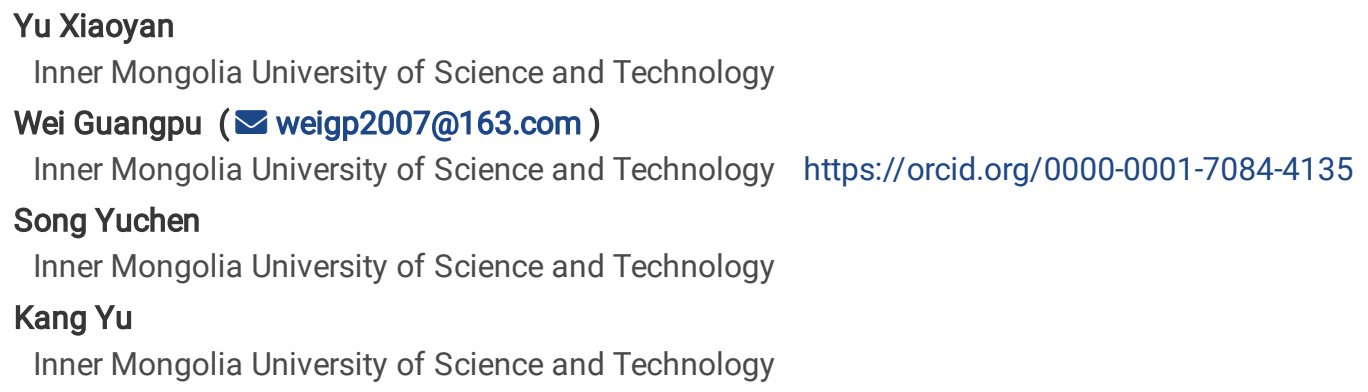




\section{Abstract}

In order to repair light rare earth soil effectively, plant and mycorrhizae technology were applied together. It will provide theoretical basis for ecological restoration of light rare earth contaminated soil. The method of greenhouse pot experiment was used in this study. The concentrations of lanthanum ( $\mathrm{La}$ ) in tested soil samples were $107.15,329.41$, and 2,031.71 mg/kg and cerium (Ce) were 362.11, 741.81,

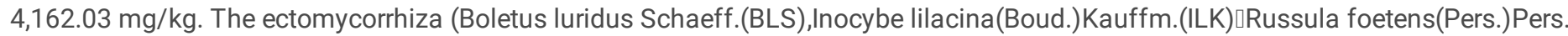
(RFP) $\square$ Lactarius sanguifluus (Paul.) Fr.(LSF)) was inoculated on Pinus tabuliformis. The inoculation rate and biomass of mycorrhiza, as well as the absorption, transfer and root retention of La and Ce, light rare earth elements (LREE) by plants were determined to provide the theoretical basis for the treatment of $\mathrm{La}$ and Ce contaminated soil. The results showed that a symbiotic relationship was established between ectomycorrhiza and Pinus tabuliformis. The mycorrhizal infection rate of Pinus tabulaeformis ranged from $0.51-64.81 \%$, The biomass results showed that the dry weight of aboveground organs and roots increased by $1.46,1.67$ and 1.88 times, $1.73,1.98$ and 2.08 times, respectively. With the increase of the concentration of $\mathrm{La}$ and $\mathrm{Ce}$ in the soil, the increase of one LREE in the host plants inoculated with mycorrhizae was greater than that in the blank control group. Following mycorrhizal inoculation, La and Ce transfer coefficients in P. and root retention coefficients increased, which may lead to the decrease of absorption and transfer capacity of hyperaccumulators. This study showed that mycorrhizae can improve the absorption of La and Ce by host plants, demonstrating potential value in the environmental remediation of LREE contaminated soil.

\section{Introduction}

With the increasing global demand for rare earth products, China is increasing the mining volume of rare earth minerals, resulting in the enrichment of exogenous rare earth in the soil and posing a serious threat to the ecological environment and human health [1]. To date, China's rare earth reserves accounted for about $23 \%$ of the world's total reserves. Bayan Obo light rare earth mine in Baotou City, Inner Mongolia, China accounts for about $85 \%$ of China's rare earth reserves [2]. Baotou city is known as the world's rare earth capital and has an open-pit mining history of more than 60 years. The content of light rare earth elements (LREE) in the soil of this area is approximately 400 times higher than the background value of Inner Mongolia. Light rare earth elements migrate throughout the soil environment, leading to many environmental issues in the soil, including farmland yield loss, soil desertification, and so on. Soil pollution by rare earth elements has proven to be of great concern [3]. Studies have shown that concentrations of exogenous rare earth in soil higher than $400 \mathrm{mg} / \mathrm{kg}$, the biomass of Oryza sativa L. significantly decreases and the plants die when the concentration is $1,500 \mathrm{mg} / \mathrm{kg}$ [4]. Therefore, the environmental damage caused by light rare earth pollution and the mechanism of phytoremediation is a problem requiring an urgent solution.

Mycorrhizae are symbiotic with some fungi and host plant roots in natural soil [5]. Mycorrhizae can expand the absorption area of plant roots and increase the absorption of nitrogen, phosphorus, potassium, and other minerals by host plants [6]. Mycorrhizae coexist with host plant roots and expand throughout the soil, absorbing nutrients from host plants on one hand and helping plant roots to absorb water and nutrients from the soil on the other hand [7]. Based on morphological and anatomical characteristics, mycorrhizae are classified into ectomycorrhizae and endomycorrhizae. Approximately $3 \%$ of plants contain ectomycorrhizae, the majority of which are trees.

Ectomycorrhizae form a mantle around the root system of the host, protecting the new root and expanding mycelia to the surrounding soil to replace the root hairs of the host plant to absorb water and nutrients. Mycorrhizal fungi play an important role in the remediation of soil polluted ecological environment through the combination of mycorrhizal fungi and host plants. In nature, mycorrhizal fungi have certain selectivity to host plants. This requires that mycorrhizal remediation should follow the principle of "suitable for plants, suitable for fungi" [8].

Mycorrhizae can improve the ability of host plants to absorb water and nutrients from the soil and enhance their resistance to stress [9]. Greenhouse pot experiment was used in this study. The soil was collected from the surface soil in Bayan Obo Mining District. In this study, we investigated the effect of ectomycorrhizaon (BLS), (ILK), (RFP), (LSF) the mycorrhizal infection rate, biomass (ground organs dry weight and root dry weight) and the absorption, transfer, and retention coefficients of La and Ce LREE of Pinus tabuliformis as well as that intraradices, to provide a theoretical basis and technical support for the environmental remediation and treatment of LREE contaminated soil.

\section{Materials And Methods}

\subsection{Soil collection and treatment}


More than $90 \%$ of the LREE in the Bayan Obo Mining District exist in the form of monazite [3]. The LREE in the soil mainly exist in the form of residue and few in the form of weak acid extracts [10]. Their soil content is high but biological activity is low, making dissociation a challenge. In addition, when exogenous LREE enter the soil, the majority remain in the surface layer, and their concentration in the soil, therefore, presents the characteristics of gradient decline [11]. Therefore, surface soil from 0 to $40 \mathrm{~cm}$ was collected in this study from the

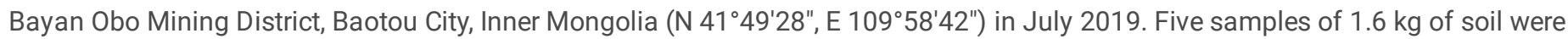
collected at each sampling point with a ring knife. Following uniform mixing, each sample was divided into 4 equal parts (each of the parts was $2 \mathrm{~kg}$ ). One part was randomly selected and reserved in a self-sealing bag [12]. The collected soil was screened with a 2-mm soil sieve and sterilized for 2 hours in an autoclave at $121^{\circ} \mathrm{C}$ [13]. The basic physicochemical properties of soil are shown in Table 1.

Table 1

Basic Physico Chemical Properties of Soils

\begin{tabular}{|c|c|c|c|c|c|c|c|c|c|c|}
\hline substance & $\mathrm{pH}$ & $\begin{array}{l}\text { Organic } \\
\text { matter }\end{array}$ & Nitrogen & $\begin{array}{l}\text { Available } \\
\text { nitrogen }\end{array}$ & Phosphorus & $\begin{array}{l}\text { Available } \\
\text { phosphorus }\end{array}$ & Potassium & $\begin{array}{l}\text { Available } \\
\text { potassium }\end{array}$ & $\begin{array}{l}\text { Bulk } \\
\text { density }\end{array}$ & $\begin{array}{l}\text { Water } \\
\text { content }\end{array}$ \\
\hline Unit & & $\%$ & g. $\mathrm{kg}^{-1}$ & $\mathrm{mg} \cdot \mathrm{kg}^{-1}$ & g. $\mathrm{kg}^{-1}$ & $\mathrm{mg} \cdot \mathrm{kg}^{-1}$ & g. $\mathrm{kg}^{-1}$ & $\mathrm{mg} \cdot \mathrm{kg}^{-1}$ & ${ }_{3}^{\mathrm{g} / \mathrm{cm}^{-}}$ & $\%$ \\
\hline Soil & 8.52 & 1.69 & 0.22 & 69.84 & 0.33 & 13.19 & 13.44 & 42.85 & 1.78 & 5.76 \\
\hline
\end{tabular}

\subsection{Plants and mycorrhizae}

Seeds of $P$. tabuliformis and L. bicolor used in this experiment were obtained from the seed management station of Baotou Municipal Bureau of Agriculture and Pastoral Administration, Inner Mongolia. Before sowing, seeds were surface sterilized and then placed in a constant temperature incubator $\left(20^{\circ} \mathrm{C}\right)$ for germination treatment. Seeds were sown when they were white. P. tabuliformis was inoculated with ectomycorrhiza IL collected in the field [14]. The inoculation agents included rhizosphere sand-soil mixture, spores, hyphae, and infected plant root segments. The inoculants were obtained by propagation in the experiment. The inoculants included sand soil mixture, spores, hyphae and infected root segments.

\subsection{Experimental design and treatment}

The greenhouse pot method was used in this study to set up three types of soil contaminated with lanthanum (La) or cerium (Ce) LREE with varying concentrations. P. tabuliformis and L. bicolor were either inoculated with ectomycorrhizae, endomycorrhizae or nothing (blank control group). Three replicates were done for each treatment, totaling 54 pots that were randomly arranged [15]. Two kg of sterilized soil and $50 \mathrm{~g}$ of inoculation agent were added to each experimental pot, while $2 \mathrm{~kg}$ of sterilized soil and $50 \mathrm{~g}$ of fungicide were added to each pot in the control group. Each pot was seeded with 5 healthy and plump germinated P. tabuliformis or L. bicolor. Thinning was carried out one week after emergence, where three plants with similar growth potential were left in each pot [16]. The experiment was carried out in the experimental greenhouse of landscape plant restoration in the dry and cold mine of Inner Mongolia University of Science and Technology, with natural lighting, temperature ranging from 21 to $35^{\circ} \mathrm{C}$, and relative humidity ranging from 32 to $60 \%$. The plants were watered regularly, and the data were collected 90 days after seedling emergence.

\subsection{Sample collection}

The above-ground organs and roots of the harvested plants were cut off, cleaned with tap water, rinsed with distilled water three times, dried at $70^{\circ} \mathrm{C}$ and weighed. The mycorrhizal infection rate was determined by collecting $1 \mathrm{~g}$ of fresh roots from randomly selected experimental plants and preserved in $50 \%$ ethanol. The root frequency standard method was used to calculate the mycorrhizal infection rate [17]. The prepared test samples were stained with $0.05 \%$ trypan blue lactate glycerol solution (lactic acid:glycerol, 1:1) and sectioned[18].

The collected soil samples were naturally air-dried, then dried at $105^{\circ} \mathrm{C}$ for 4 hours, and sieved through a 100-mesh sieve to remove impurities. Then, $0.20 \mathrm{~g}$ of both the reserved soil samples and the standard soil samples were weighed and placed in a tetrafluoroethylene digestion tank for digestion [19]. The content of La and Ce in soil samples was determined by Inductively Coupled Plasma Mass Spectrometer (ICP-MS, NexION 300Q, PerkinElmer) [20].

After the above-ground organs and roots of the plants were cleaned, they were dried for 4 hours at $105^{\circ} \mathrm{C}$, ground, and screened for use through a 100 -mesh sieve. Then, $0.25 \mathrm{~g}$ of both types of soil were weighed and digested with Multiwave 3000 microwave digestion apparatus. The contents of La and Ce LREE were determined by ICP-MS [21].

\subsection{Data processing}

Page 3/11 
The infection rate was calculated using the following formula [18]: Mycorrhizal infection rate $=$ (number of infected root segments $/$ total number of observed root segments) $\times 100 \%$

The formula of the biological transfer coefficient (BTC) [22] was as follows:

Where Tu is the content of above-ground organs of plants; Tr is the root content of plants. BTC reflects the ability of plants to transfer La and Ce LREE from roots to above-ground organs. When BTC is less than 1, the transfer ability is weak. When BTC is greater than 1 , the transfer ability is strong and when active absorption occurs [23-25].

The root retention coefficient (RC) [26] was calculated as follows:

Excel 2017 and SPSS 19.0 were used for data calculation and variance analysis to test the significance of the difference between samples or treatments. The difference was considered to be significant or very significant if the P-value was less than 0.05 or less than 0.01 , respectively.

\section{Results}

\subsection{Mycorrhizal infection rate and plant biomass}

At various concentrations of La and Ce polluted soil, the infection rate and biomass of $P$. tabuliformis were measured by inoculating ectomycorrhiza. There was no mycorrhizal infection in the control group. The measured data are shown in Table 2.

According to La and Ce concentrations in the soil (Table 2), the tested soil was divided into three concentration zones: high concentration $(2,031.74,4,162.03 \mathrm{mg} / \mathrm{kg})$, medium concentration $(329.41,741.81 \mathrm{mg} / \mathrm{kg})$, and low concentration $(107.15,362.11 \mathrm{mg} / \mathrm{kg})$. Plants successfully established a symbiotic relationship with the tested mycorrhiza. The infection rate of ectomycorrhiza in $P$. tabuliformis was lower than that of endomycorrhizae in L. bicolor. There was no mycorrhizal infection in the control group. The mycorrhizal infection rate of P. tabuliformis ranged from 1.18 to $34.16 \%$, while the rate in L. bicolor ranged from 0.51 to $64.81 \%$ (among which BLS was the highest). The mycorrhizal infection rate of the plants decreased with the increase of LREE concentration. The biomass of above-ground organs and roots of $P$. tabuliformis and L. bicolor decreased significantly with the increase of LREE concentration. The biomass of theplants both increased after inoculation. The dry weight of above-ground organs of $P$. tabuliformis in different soil samples increased $1.59,1.19$ and 1.03 times, respectively. The dry weight of roots increased $1.86,1.30$ and 1.30 times, respectively. The biomass of $L$. bicolor inoculated with BLS mycorrhiza increased the most, with the dry weight of above-ground organs increasing 1.46, 1.67 and 1.88 times, respectively, and the dry weight of roots increasing $1.73,1.98$ and 2.08 times, respectively. 
Table 2

Effects of inoculation with Mycorrhizal Colonization and Biomass of Pinus

\begin{tabular}{|c|c|c|c|c|c|c|}
\hline \multirow[t]{2}{*}{ Plants } & \multirow[t]{2}{*}{ Mycorrhizal name } & \multicolumn{2}{|c|}{ Inoculation( mg/kg) } & \multirow[t]{2}{*}{ Mycorrhizal infection rate(\%) } & \multirow[t]{2}{*}{ Shoot dry weight(g) } & \multirow[t]{2}{*}{ Root dry weight(g) } \\
\hline & & La & $\mathrm{Ce}$ & & & \\
\hline \multirow[t]{15}{*}{ Pinus } & \multirow[t]{3}{*}{ BLS } & 2031.71 & 4162.03 & $4.36 \pm 0.39$ & $3.98 \pm 0.49 b$ & $2.26 \pm 0.16 b$ \\
\hline & & 329.41 & 741.81 & $35.75 \pm 2.79$ & $8.12 \pm 0.22 b$ & $4.87 \pm 0.65 a$ \\
\hline & & 107.15 & 362.11 & $64.81 \pm 6.33$ & $12.57 \pm 0.46 a$ & $6.93 \pm 0.77 b$ \\
\hline & \multirow[t]{3}{*}{ ILK } & 2031.71 & 4162.03 & $2.57 \pm 0.02$ & $3.59 \pm 0.58 b$ & $1.37 \pm 0.64 b$ \\
\hline & & 329.41 & 741.81 & $28.83 \pm 1.83$ & $5.56 \pm 0.89 b$ & $3.34 \pm 0.25 a$ \\
\hline & & 107.15 & 362.11 & $42.23 \pm 3.93$ & $9.11 \pm 0.55 a$ & $3.42 \pm 0.37 a$ \\
\hline & \multirow[t]{3}{*}{ RFP } & 2031.71 & 4162.03 & $0.51 \pm 0.01$ & $3.12 \pm 0.12 a$ & $1.32 \pm 0.41 \mathrm{~b}$ \\
\hline & & 329.41 & 741.81 & $25.24 \pm 1.09$ & $5.51 \pm 0.35 b$ & $3.27 \pm 0.28 a$ \\
\hline & & 107.15 & 362.11 & $39.03 \pm 3.37$ & $7.88 \pm 0.97 a$ & $3.86 \pm 0.32 b$ \\
\hline & \multirow[t]{3}{*}{ LSF } & 2031.71 & 4162.03 & $1.18 \pm 0.02$ & $1.16 \pm 0.27 b$ & $0.26 \pm 0.01 b$ \\
\hline & & 329.41 & 741.81 & $13.53 \pm 1.63$ & $2.43 \pm 0.61 a$ & $0.73 \pm 0.03 a$ \\
\hline & & 107.15 & 362.11 & $34.16 \pm 3.18$ & $3.20 \pm 0.24 b$ & $1.22 \pm 0.05 a$ \\
\hline & \multirow[t]{3}{*}{$\mathrm{CK}$} & 2031.71 & 4162.03 & $0.00 \pm 0.00$ & $0.73 \pm 0.33 a$ & $0.14 \pm 0.01 a$ \\
\hline & & 329.41 & 741.81 & $0.00 \pm 0.00$ & $2.04 \pm 0.17 b$ & $0.56 \pm 0.01 \mathrm{a}$ \\
\hline & & 107.15 & 362.11 & $0.00 \pm 0.00$ & $3.11 \pm 0.74 a$ & $0.94 \pm 0.02 a$ \\
\hline
\end{tabular}

Note: the data in the table are the average value \pm standard error of three repetitions. Different letters in the same column indicate significant difference, a indicates significant difference $(P<0.05)$, B indicates significant difference $(P<0.01)$

\subsection{La and Ce content in Pinus tabuliformis}

The tested soil was divided into a high concentration zone, medium concentration zone, and low concentration zone (Table 3). With the increase in the content of LREE ( $\mathrm{La}$ and $\mathrm{Ce}$ ) in the soil, the content of LREE in P. tabuliformis also increased, while the content in aboveground organs was lower than that in the root system. After IL mycorrhizal inoculation, the La element transfer coefficient of $P$. tabuliformis decreased by $0.00,-0.17$, and -0.15 and the root retention coefficient increased by $0.00,0.17$, and 0.10 . The Ce element transfer coefficient decreased by $-0.02,-0.07$, and -0.15 and the root retention coefficient increased by $0.02,0.07$, and 0.15 . 
Table 3

Content of La and Ce Light Rare Earth Elements in Pinus

\begin{tabular}{|c|c|c|c|c|c|c|}
\hline \multirow[t]{2}{*}{ Element } & \multirow[t]{2}{*}{ Plant organs } & \multicolumn{5}{|l|}{ Pinus } \\
\hline & & BLS & ILK & RFP & LSF & $\mathrm{CK}$ \\
\hline \multirow[t]{6}{*}{ La } & \multirow{3}{*}{$\begin{array}{l}\text { Shoot } \\
(\mathrm{mg} / \mathrm{kg})\end{array}$} & $57.34 \pm 5.33$ & $53.53 \pm 5.22$ & $51.13 \pm 4.87$ & $50.95 \pm 4.13$ & $20.63 \pm 2.13$ \\
\hline & & $881.82 \pm 50.09$ & $683.47 \pm 66.07$ & $641.61 \pm 57.33$ & $191.42 \pm 11.01$ & $183.46 \pm 10.92$ \\
\hline & & $94.62 \pm 9.32$ & $90.76 \pm 9.58$ & $81.67 \pm 9.58$ & $34.12 \pm 4.59$ & $25.10 \pm 3.39$ \\
\hline & \multirow{3}{*}{$\begin{array}{l}\text { Root } \\
(\mathrm{mg} / \mathrm{kg})\end{array}$} & $62.30 \pm 6.24$ & $57.90 \pm 4.91$ & $55.34 \pm 3.35$ & $6.90 \pm 1.24$ & $2.94 \pm 0.50$ \\
\hline & & $754.99 \pm 78.33$ & $585.75 \pm 58.51$ & $540.93 \pm 43.46$ & $254.02 \pm 23.04$ & $245.59 \pm 20.76$ \\
\hline & & $86.00 \pm 8.89$ & $76.89 \pm 8.93$ & $67.44 \pm 3.18$ & $46.75 \pm 8.76$ & $27.94 \pm 2.45$ \\
\hline \multirow[t]{6}{*}{$\mathrm{Ce}$} & \multirow{3}{*}{$\begin{array}{l}\text { Shoot } \\
(\mathrm{mg} / \mathrm{kg})\end{array}$} & $59.47 \pm 5.34$ & $53.55 \pm 2.45$ & $53.97 \pm 5.24$ & $9.42 \pm 1.24$ & $3.53 \pm 0.11$ \\
\hline & & $1484.21 \pm 110.37$ & $1272.38 \pm 132.24$ & $1078.31 \pm 94.58$ & $234.41 \pm 7.27$ & $227.17 \pm 11.47$ \\
\hline & & $258.39 \pm 28.51$ & $255.71 \pm 21.29$ & $249.04 \pm 17.82$ & $58.03 \pm 3.16$ & $47.36 \pm 6.24$ \\
\hline & \multirow{3}{*}{$\begin{array}{l}\text { Root } \\
\text { (mg/kg) }\end{array}$} & $106.77 \pm 11.87$ & $91.14 \pm 7.19$ & $84.26 \pm 6.82$ & $17.47 \pm 1.51$ & $8.06 \pm 1.18$ \\
\hline & & $1292.09 \pm 133.28$ & $1173.67 \pm 111.20$ & $971.99 \pm 86.35$ & $289.34 \pm 18.89$ & $273.24 \pm 28.85$ \\
\hline & & $218.02 \pm 20.49$ & $208.21 \pm 16.89$ & $231.38 \pm 19.24$ & $78.85 \pm 8.10$ & $58.48 \pm 4.89$ \\
\hline
\end{tabular}

The contaminated soil was divided into high concentration area, medium concentration substrate and low concentration substrate, and then the tolerant earthworm was added to the test. Pinus tabulaeformis was inoculated with ectomycorrhizal BLS, ILK, RFP and LSF respectively, and the blank control group was set up. The results showed that the contents of pollutants absorbed by Pinus tabulaeformis were as follows: high concentration zone > medium concentration zone > low concentration zone; the contents of pollutants in organs of Pinus tabulaeformis were root $>$ stem > leaf, and the contents of pollutants absorbed by Pinus tabulaeformis inoculated with mycorrhiza were $\mathrm{BLS}>\mathrm{ILK}>\mathrm{RFP}>\mathrm{LSF}$.

\subsection{La and Ce content in Lespedeza bicolor}

With the increase of La and Ce content in the soil, the content of LREE in L. bicolor also increased, while the content in above-ground organs was greater than in the roots (Table 5). The content of LREE increased following inoculation with RI, FM and GV. LREE content was highest in L. bicolor inoculated with RI. The La element transfer coefficient of L. bicolor inoculated with RI decreased by $-0.02,-0.11$, and 0.04 and the root retention coefficient increased by $0.02,0.12$, and 0.04 . The Ce element transfer coefficient increased by $0.06,0.07$, and 0.04 , while the root retention coefficient decreased by $0.06,0.11$, and -0.04 . 
Table 4

Content of La and Ce Light Rare Earth Elements in Pinus

\begin{tabular}{|c|c|c|c|c|c|c|}
\hline Name & La & BCT & $\mathrm{RC}$ & $\mathrm{Ce}$ & BCT & $\mathrm{RC}$ \\
\hline \multirow[t]{3}{*}{ BLS } & 2031.71 & 1.17 & -0.17 & 4162.03 & 1.15 & -0.15 \\
\hline & 329.41 & 1.10 & -0.10 & 741.81 & 1.19 & -0.19 \\
\hline & 107.15 & 1.05 & -0.05 & 362.11 & 1.02 & -0.02 \\
\hline \multirow[t]{3}{*}{ ILK } & 2031.71 & 1.17 & -0.17 & 4162.03 & 1.08 & -0.08 \\
\hline & 329.41 & 1.18 & -0.18 & 741.81 & 1.23 & -0.23 \\
\hline & 107.15 & 1.08 & -0.08 & 362.11 & 1.09 & -0.09 \\
\hline \multirow[t]{4}{*}{ RFP } & 2031.71 & 1.19 & -0.19 & 4162.03 & 1.11 & -0.11 \\
\hline & 329.41 & $1 . .21$ & -0.21 & 741.81 & 1.08 & -0.08 \\
\hline & 107.15 & 1.03 & -0.03 & 362.11 & 1.04 & -0.04 \\
\hline & 2031.71 & 0.75 & 0.25 & 4162.03 & 0.81 & 0.19 \\
\hline \multirow[t]{2}{*}{ LSF } & 329.41 & 0.73 & 0.27 & 741.81 & 0.74 & 0.26 \\
\hline & 107.15 & 0.73 & 0.27 & 362.11 & 0.72 & 0.28 \\
\hline \multirow[t]{3}{*}{$\mathrm{CK}$} & 2031.71 & 1.19 & -0.19 & 4162.03 & 1.09 & -0.09 \\
\hline & 329.41 & 1.22 & -0.22 & 741.81 & 1.08 & -0.08 \\
\hline & 107.15 & 1.09 & -0.09 & 362.11 & 0.98 & 0.02 \\
\hline
\end{tabular}

The tested soil was divided into three concentration zones (Fig. 1). The plant species were inoculated with mycorrhizae while the control group was not. The results showed that LREE content absorbed by the plants was as follows: high concentration zone $>$ medium concentration zone > low concentration zone. The LREE content in plants was as follows: mycorrhizae-inoculated plants > control group. LREE content in L. bicolor inoculated with four mycorrhizae was as follows: BLS > ILK > RFP > LSF.

\section{Discussion}

Mycorrhizal infection rate is an index to measure the affinity between mycorrhizae and host plants [27]. The infection rate is affected by various factors, such as soil nutrients, types and concentrations of pollutants, and the combination of strains and host plants [28]. In this study, we found that in the light rare earth elements La and Ce polluted soil, the plants developed symbiotic relationships with mycorrhizae, indicating that the mycorrhiza could survive and reproduce under the certain concentration of LREE contamination in the soil [26]. The infection rate of ectomycorrhiza in P. tabuliformis ranged from BLS 4.36-64.81\%, ILK 2.57-42.23\%, RFP 0.51-39.03\%, and LSF1.18 $-34.16 \%$. The mycorrhizal infection rates in this study were slightly lower in comparison to previously published studies. Studies have shown that the infection rate of endomycorrhiza in Zea mays in Ce contaminated soil ranges from 5.29 to $78.79 \%$ [13]. Similarly, the infection rate of mycorrhiza in Glycine max L. in Ce contaminated soil is $67.46 \%$ [29]. The primary reason for this variation lies in the high concentration of LREE in the soil tested in this study. In addition, this study found that both the biomass of above-ground organs and the roots of the plants decreased significantly with the increase of LREE concentration. When the concentration of element La increased by about 19 times and the concentration of element Ce increased by about 11 times, the dry weight of above-ground organs in $P$. tabuliformis increased by approximately $36.25 \%$, the dry weight of roots increased by approximately $21.31 \%$, the dry weight of above-ground organs in L. bicolor increased by $31.66-47.21 \%$ and the dry weight of roots increased by $32.61-40.06 \%$. Our study showed a lower biomass increase compared to previously published data. The dry weight of above-ground organs and roots of Lolium perenne and Cynodon dactylon. Inoculated with mycorrhiza Glomus aggregatum and Glomus constrictum increased by $203 \%$ vs. $482 \%$ and $119 \%$ vs. $291 \%$, respectively [29]. Inoculation of mycorrhiza Glomus versiforme increased the dry weight of organs and roots of Elymus dahericus by $83 \%$ and 103\% [30]. The fresh weight of Brassica campestris decreased by about 76\% when the Ce element concentration increased from 5 $\mathrm{mg} / \mathrm{L}$ to $100 \mathrm{mg} / \mathrm{L}$ [31]. Increased Ce content in soil resulted in decreased biomass of host plant Raphanus sativus L. [32]. In this study and other studies, the "Hormesis" effect of mycorrhizal infection rate increasing first and decreasing later appeared with the increase of 
LREE concentration [33]. Therefore, it is feasible to repair the symbiosis between mycorrhiza and host plants in the soil contaminated with a certain concentration of LREE.

The results of this study showed that after the inoculation of mycorrhiza in P. tabuliformis and L. bicolor, the content of La and Ce LREE in the plants increased with the content of LREE in the soil. Other studies have found that the La element significantly increased in host plants after mycorrhiza inoculation in soils contaminated with La element [34]. When the soil contains a low concentration of La element, mycorrhiza inoculation can increase the content of La in Astragalus sinicus [35]. The above results show that mycorrhizal inoculation can increase the host plant's LREE absorption at certain LREE concentrations. The absorption mechanism may be that mycorrhizae increase the channels through which host plants absorb nutrients such as phosphorus, and at the same time increase the absorption of light rare earth elements. Therefore, the mechanism and interaction of mycorrhizal absorption of LREE should be further investigated.

In this study, we found that $P$. tabuliformis reduced the transfer coefficients and increased the root retention coefficients following mycorrhizal inoculation. Some studies have found that in soils contaminated with elements La and Pb (lead) at different concentrations, mycorrhizal inoculation significantly reduced the $\mathrm{Pb}$ content in above-ground organs of maize and increased the $\mathrm{Pb}$ content in roots, effectively inhibiting the transfer of Pb pollutants from roots to above-ground organs [36]. Other studies have shown that endomycorrhizal inoculation in host plants can catalyze the synthesis of chelated synthase (PCs), chelate heavy metal ions in the cytoplasm, transfer heavy metal ions to plant vacuoles, and effectively improve host plant tolerance [37]. Under the chelation of mycorrhizal hyphae and glomamycin, heavy metal ions are fixed to produce filtration effect, reducing the heavy metal ions entering the host plants, thus reducing the transfer ability [38]. Mycorrhizae influence $\mathrm{Pb}$ enrichment in plants, and a large amount of $\mathrm{Pb}$ is fixed in the root by mycelia and vesicles, which reduce the transfer rate from root to above-ground organs [39], consistent with the results obtained in this study. Therefore, mycorrhizae have a negative effect on the host plant's transfer of LREE in La and Ce polluted soil, leading to a decrease in the transfer ability of hyperaccumulators. This may be related to the interaction between mycorrhizae, host plant, LREE, and heavy metal ions. It is therefore necessary to study the mechanism of the absorption, transfer, and retention of mycorrhizae-inoculated hosts in LREE contaminated soil.

\section{Conclusions}

(1) In the soils polluted by three different concentrations of La and Ce LREE, symbiotic relationship between ectomycorrhizae and $P$. tabuliformis, endomycorrhizae and L. bicolor was successfully established. The mycorrhizal infection rate and plant biomass increased first and then decreased with the increase of LREE concentration.

(2)The decrease of transfer coefficient and the increase of root retention coefficient indicated that $P$. tabuliformis belonged to passive absorption, and there was no significant change in transfer efficiency, as it could only be used as an auxiliary plant in light rare earth ecological restoration.

(3) The results show that mycorrhizae and host plants have potential application value for the environmental remediation of La and Ce contaminated soil. Further research should focus on the infection rate of the most appropriate concentration of LREE, mycorrhizae, and host plant selection.

\section{Declarations}

Author Contributions囚Conceptualization, Yu X. and Wei G.; supervisor, Song Y. and ; formal analysis, Gao Y.; writing-original draft preparation, Yu X.; writing-review and editing, Wei G. and Xiao F. All authors have read and agreed to the published version of the manuscript.

Funding: This research was funded by Natural Science Foundation of Inner Mongolia Autonomous Region (2018LH07002) and 2017MS (LH)0305.

Conflicts of Interest: The authors declare no conflict of interest.

\section{References}

1. Germund T. Rare earth elements in soil and plant systems-A review. Plant and Soil 2004, (267):191-206.

2. Balaram V. Rare earth elements: A review of applications, occurrence, exploration, analysis, recycling, and environmental impact. Geoscience Frontiers 2019, 10(04):1285-1303. 
3. Guo W; Fu R.Y.; Zhao R.X.; Zhao W.J.; Guo J.Y.; Zhang J. Distribution characteristics and current situation of soil rare earth contamination in the Bayan Obo Mining Area and Baotou tailing reservoir in Inner Mongolia. Environmental Science 2013, 34(5):18951900.

4. Wang L.; Hu A.; Zhou Q.; Liang T.; Wang X.; Yan X. Accumulation and Fractionation of Rare Earth Elements in Soil-Rice System. Journal of the Chinese Rare Earth Society 2006, 1:91-97.

5. Hallet P.D.; Feeney D.S.; Bengough A.G.; Hallett, P.D.; Feeney, D.S.; Bengough, A.G.; Rillig, M.C.; Scrimgeour, C.M.; Young, I.M. Disentangling the impact of AM fungi versus roots on soil structure and water transport. Plant and Soil 2009, 314(1-2):183-196区

6. Grunwald U.; Guo W.B.; Fischer K.; Isayenkov S.; Ludwig-Müller J.; Hause B.; Yan X.; Küster H.; Franken P. Overlapping expression patterns and differential transcript levels of phosphate transporter genes in arbuscular mycorrhizal, P-i-fertilised and phytohormonetreated Medicago truncatula roots. Planta 2009, 229(5):1023-1034区

7. Karimi A.; Khodaverdiloo H.; Sepehri M.; Sadaghiani M.R. Arbuscular mycorrhizal fungi and heavy metal contaminated soils. African Journal of Microbiology Research 2011, 5(13):1571-1576》

8. Cameron D.D. Arbuscular mycorrhizal fungi as (agro) ecosystem engineers. Plant and Soil, 2010, 333(1-2): 1-5》

9. Hallett P.D.; Feeney D.S.; Bengough G.A.;:Rilling M.C.; Scrimgeour C.M.; Young I.M. Disentangling the impact of AM fungi versus roots on soil structure and water transport. Plant and Soil, 2009, 314(1-2):183-196》

10. Wang X.F.; Xu C.X.; Gu X.; Wang Y.P.; Li K.; Bao Z.Y. Concentration and Fractionation of Rare Earth Elements in Soils Surrounding RareEarth Ore Area. Rock and Mineral Analysis 2019, 38(2):137-146.

11. Ding S.M.; Zhang Z.L.; Lang T.; Sun Q.; Li S. Effect of Extraneous Rare Earths (REs) on Form of Soil Exchangeable REs and Heavy Metals. Environmental Science 2003, 4:122-126.

12. Wei G.; Yan W.; Yu X.; Wei J.; Xiao F. Selection of La and Ce Hyper-Tolerant Plants for Vegetation Rehabilitation in Light Rare Earth Tailling. Scientia Silvae Sinicae 2019, 55(5):20-26.

13. Wang F.; Guo W.; Ma P.K.; Pan L.; Zhang J. Effects of Arbuscular Mycorrhizal Fungi on the Growth and Ce Uptake of Maize Grown in Ce-contaminated Soils. Environmental Science 2016, 37(1):309-316.

14. Wei J.; Yan W. The list of ectomycorrhizal fungi of Pinus tabulaeformis. Northern Horticulture 2015(3):126-130.

15. Kazantseva O.; Bingham M.; Simard S.W.; Berch S.M. Effects of growth medium, nutrients, water, and aeration on mycorrhization and biomass allocation of greenhouse-grown interior Douglas-fir seedlings. Mycorrhiza 2009, 20(1):51-66.

16. Zhang H.; Tang M.; Chen H.; Tian, Z.; Xue Y.; Feng Y. Communities of arbuscular mycorrhizal fungi and bacteria in the rhizosphere of Caragana korshinkii and Hippophae rhamnoides in Zhifanggou watershed. Plant and Soil 2010, 326(1-2):415-424.

17. Biermann B.; Linderman R.G. Quantifying vesicular-arbuscular mycorrhizae:a proposed method towards standardization. New Phytologist 1981, 87(1): 63-67》

18. Phillips J.M.; Hayman D.S. Improved procedures for clearing roots and staining parasitic and vesicular-arbuscular mycorrhizal fungi for rapid assessment of infection. Transactions of the British Mycological Society 1970, 55(1): 158-160区

19. Liu Y.; Diwu C.; Zhao Y.; Liu X.; Yuan H.; Wang J. Determination of trace and rare-earth elements in Chinese soil and clay reference materials by ICP-MS. Chinese Journal of Geochemistry 2014(33):95-102.

20. Masson P.; Dalix T. Comparison of open digestion methods for the determination of rare earth elements in plant samples by ICP-MS. Communications in Soil Science and Plant Analysis 2016, 47(16):1866-1874.

21. Zhang L.; Liu J.; Zhang Y. Distribution Characteristics of Rare Earth Elements in Plants and Soils from the Bayan Obo Mining Area. Rock and Mineral Analysis 2019, 38(5):556-564区

22. Salt D.E., laylock M.; Kumar N.P.; Dushenkov V.; Ensley B.D.; Chet I. Phytoremediation: a novel strategy for the removal of toxic metals from the environment using plants. Bio/technology (Nature Publishing Company) 1995, 13(5):468-474区

23. Henriques F.S.; Fernandes J.C. Metal uptake and distribution in rush(Juncus conglomeratus L.)plants growing in pyrites mine tailings at Lousal, Portugal. The Science of the Total Environment 1991, 12(6):779-784.

24. Pugazholi P.; Babypriya A.; Esai Kanaga Yadav K.R.. Phytoremediation: Removal of Heavy Metals from Soil using Helianthus Annuus. Research Journal of Engineering and Technology 2013, 4(4):242-245.

25. Abdolkarim C.; Mitra N.; HosseinL.Y. Phytoremediation of heavy-metal-polluted soils: Screening for new accumulator plants in Angouran mine (Iran) and evaluation of removal ability. Ecotoxicology and Environmental Safety 2009, 72(5):1349-1353.

26. Zhou L.; Cao M.; Zheng C.; Cheng W.; Bao P.; Wu Y. The potential effect of Medicago Sativa inoculated with arbuscular mycorrhizal fungi on remedying petroleum contaminated soil. Chinese Journal of Applied and Environmental Biology 2020, 3:1-17. 
27. Gao Y.; Zong J.; Que H.; Zhou Z.; Xiao M.; Chen S. Inoculation with arbuscular mycorrhizal fungi increases glomalin-related soil protein content and PAH removal in soils planted with Medicago sativa L.. Soil Biol Biochem 2018, 115: 148-151.

28. Chen B.D.; Sun Y.Q.; Zhang X.; Wu S.L.Underlying mechanisms of the heavy metal tolerance of mycorrhizal fungi . Environ Sci. 2015, 36(3): 1123-1133.

29. Chen Z.; Cao X.; Peng A.; Xun Z.; Gao Y.; Kong H. Impacts of Arbuscular Mycorrhizal Fungi and Water Conditions on Plant Growth in Rare Earth Tailings. Journal of Agro-Environment Science 2012, 31(11):2101-2107.

30. Guo W.; Zhao R.; Yang H., Zhao J.; Zhang J. Using native plants to evaluate the effect of arbuscular mycorrhizal fungi on revegetation of iron tailings in grasslands. Biology and Fertility of Soils 2013, 49 (6):617-626.

31. Wang X.; Xu H.; Liu T. Comparison of the physiological response of chinese cabbage between cerium and lead stress. Journal of Nuclear Agricultural Sciences 2010, 24(3): 634-638.

32. Ye Y.; Jin J.; Zhu F.; Zhang Q.; Zhuo Y.; Feng W. Effects of Rare Earth Element Ce3 ${ }^{+}$on Growth and Development of Radish Seedlings. Journal of University of Science and Technology of Suzhou(Natural Science Edition) 2008,25(2):44-48》

33. Sun Q.; Sun L.; Feng S.; Guo S. Effect of La (3+) on seed germination and seedling growth of Salvia miltiorrhiza. Journal of Rare Earths 2018, 36(08):898-902.

34. Chen X.H.; Zhao B. Arbuscular mycorrhizal fungi mediated uptake of nutrient elements by Chinese milk vetch (Astragalussinicus) grown in lanthanum spiked soil. Biology and Fertility of Soils 2009, 45(6): 675-678》

35. Chen B.D.; Zhu Y.G.; Duan J.; Xiao X.Y.; Smith S.E. Effects of the arbuscular mycorrhizal fungus Glomus mosseae on growth and metal uptake by four plant species in copper mine tailings. Environmental Pollution 2007, 147(2): 374-380区

36. Xiong S.; Xiong Z. Interactive Effects of La and Pb on Plant Growth and Bioaccumulation of La and Pb in Brassica juncea crispifolia. Journal of Huazhong Agricultural University (Natural Science Edition) 2007, 2:199-202.

37. Shim D.; Kim S.; Choi Y.; Song W.Y.; Park J.; Youk E.S.; Jeong S.C.; Martinoia E.; Noh E.W.; Lee Y. Transgenic poplar trees expressing yeast cadmium factor 1 exhibit the characteristics necessary for the phytoremediation of mine tailing soil. Chemosphere 2013, 90(4):1478-1486.

38. Hildebrandt U.; Regvar M.; Bothe H. Arbuscular mycorrhiza and heavy metal tolerance. Phytochemistry 2006, 68(1):139-146.

39. Yang Y.R. The mechanisms of arbuscular mycorrhizal fungi (AMF) in improving phytoremediation efficiency of lead contiminated soil. Doctoral Dissertation, Northwest A\&F University, Yangling of China, 2015.

\section{Figures}

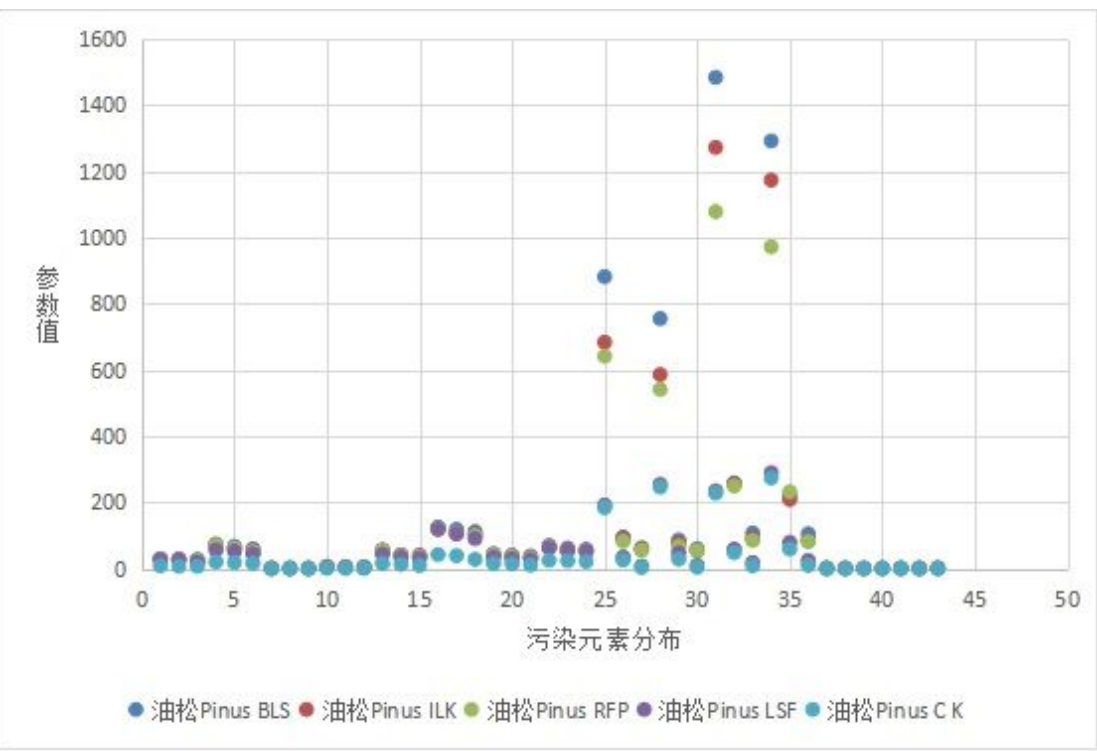

\section{Figure 1}

Content in Plant Inoculated with Mycorrhiza 


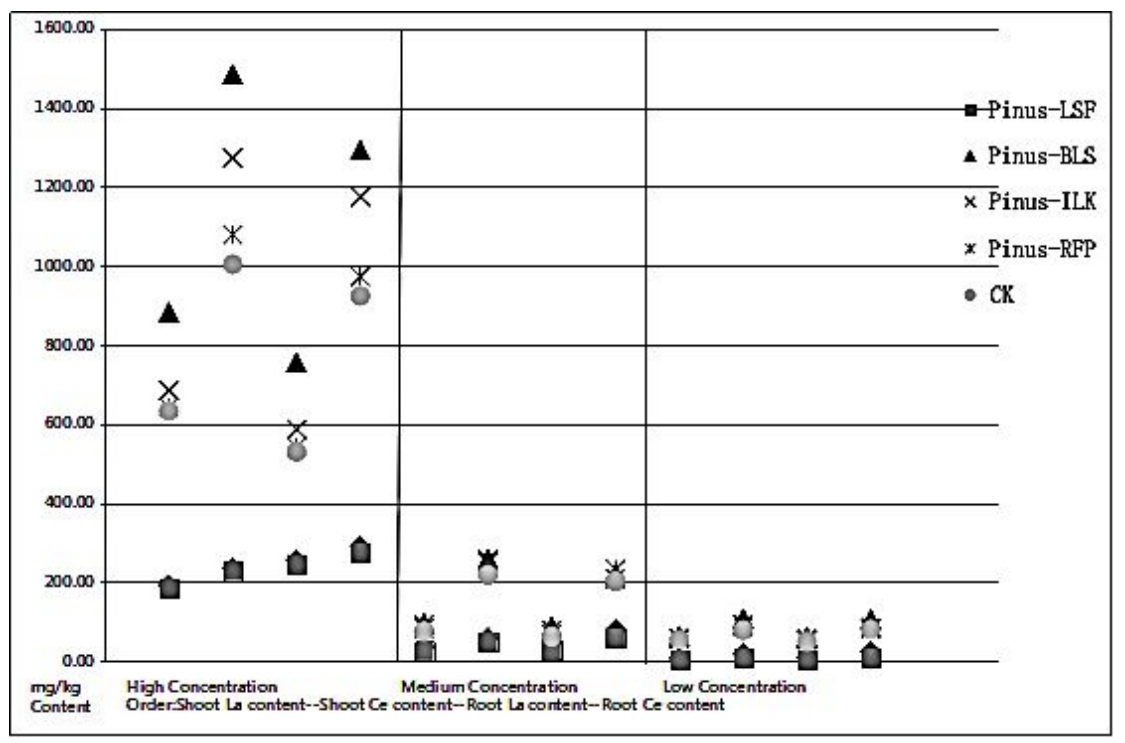

Figure 2

Content of La and Ce Light Rare Earth in Plant Inoculated with Mycorrhiza 